\title{
Determining the neuroprotective effects of dextromethorphan in lipopolysaccharide-stimulated BV2 microglia
}

\author{
WENJING CHENG ${ }^{1 *}$, YUNHONG LI $^{1 *}$, XIAOLIN HOU $^{2}$, BIN BAI $^{2}$, FAN LI $^{1}$, \\ FEIJIA DING ${ }^{1}$, JIAO MA ${ }^{1}$, NAN ZHANG ${ }^{1}$, YING SHEN ${ }^{3}$ and YIN WANG ${ }^{1}$ \\ ${ }^{1}$ Ningxia Key Laboratory of Cranial Cerebral Diseases, Basic Medical College of Ningxia Medical University, \\ Yinchuan, Ningxia 750004; ${ }^{2}$ Department of Neurology, The General Hospital of Ningxia Medical University, \\ Yinchuan, Ningxia 750004; ${ }^{3}$ Department of Neurobiology, Key Laboratory of Medical Neurobiology \\ of the Ministry of Health, Zhejiang Province Key Laboratory of Neurobiology, Zhejiang \\ University School of Medicine, Hangzhou, Zhejiang 310058, P.R. China
}

Received November 28, 2013; Accepted July 21, 2014

DOI: $10.3892 / \mathrm{mmr} .2014 .2794$

\begin{abstract}
Microglial activation has been recognized as being vital in the pathogenesis of several neurodegenerative disorders. Therefore, the identification of therapeutic drugs to prevent microglial activation and thus protect against inflammation-mediated neuronal injury, is required. In the present study, dextromethorphan (DM), a compound widely used in antitussive remedies that has been demonstrated to possess neuroprotective effects, was shown to reduce proinflammatory mediator production in lipopolysaccharide (LPS)-stimulated BV2 mouse microglial cells. Western blot analysis revealed that DM markedly suppressed the activation of nuclear factor- $\kappa \mathrm{B}(\mathrm{NF} \kappa \mathrm{B})$, caspase-3 signaling and the expression of another inflammation-inducing factor, heat shock protein 60 (HSP60) and heat shock factor-1, induced by LPS in BV2 cells. Results from ELISA assay demonstrated that DM reduced the release of HSP60, nitric oxide (NO), inducible NO synthase, tumor necrosis factor- $\alpha$, interleukin (IL)- $1 \beta$ and IL- 6 induced by LPS in BV2 microglia. These results were confirmed by immunofluorescence, suggesting that DM may exert a neuroprotective and anti-inflammatory effect by inhibiting microglial activation through the HSP60-NFKB signaling pathway. Therefore, DM may offer substantial therapeutic benefits in the treatment of neurodegenerative diseases that are accompanied by microglial activation.
\end{abstract}

Correspondence to: Professor Yin Wang, Ningxia Key Laboratory of Cranial Cerebral Diseases, Basic Medical College of Ningxia Medical University, 1160 Shengli Street, Yinchuan, Ningxia 750004, P.R. China

E-mail: yin-wang@hotmail.com

${ }^{*}$ Contributed equally

Key words: dextromethorphan, heat shock protein 60, nuclear factor $\kappa \mathrm{B}, \mathrm{BV} 2$ microglia

\section{Introduction}

Microglial cells, resident brain macrophages of the central nervous system (CNS), are pivotal in the pathogenesis of several neurodegenerative diseases (1). Microglia are activated in response to stress, and are involved in innate and adaptive immune responses by inducing the production of various pro-inflammatory mediators, including nitric oxide (NO), inducible NO synthase (iNOS), tumor necrosis factor- $\alpha$ (TNF- $\alpha$ ), interleukin-1 $\beta$ (IL-1 $\beta$ ), IL-6, nuclear factor- $\kappa \mathrm{B}$ $(\mathrm{NF} \kappa \mathrm{B})$, caspase-3 and heat shock protein (HSP) 60 (2-6), all of which contribute to neurodegeneration $(7,8)$. A number of microglia-targeted pharmacotherapies, such as protein kinase $\mathrm{C}$ inhibitors and microglia-inhibiting factors, have been proposed to suppress microglial activation and promote neuronal survival in vivo (9-11). However, the inability of these drugs to penetrate the blood-brain barrier and the complexity of current pharmacological agents, as well as the possible side effects, has halted long-term clinical use in the treatment and prevention of diseases of the CNS (12).

Dextromethorphan (DM), a derivative of morphinan, is one of the most widely used non-opioid cough suppressants, acting as the active ingredient in numerous antitussive formulations (13). As an antitussive, DM is superior to opioids used at antitussive doses in that DM lacks any gastrointestinal side effects, such as constipation, and produces a lower degree of depression of the CNS. DM is rapidly absorbed from the gastrointestinal tract, where it enters the bloodstream and crosses the blood-brain barrier (14). The anticonvulsant and neuroprotective properties of DM have been demonstrated, and treatment with DM has been shown to improve the cerebrovascular and functional consequences of global cerebral ischemia (14). However, the mechanisms underlying the neuroprotective effects of DM remain poorly understood.

Previous studies have demonstrated that naloxone, another analogue of morphinan, protects against lipopolysaccharide (LPS)-induced neurotoxicity in vitro and in vivo through the inhibition of the release of proinflammatory factors and free radicals (15-18). DM is structurally similar to naloxone and has been shown to protect against LPS-induced dopamine 
neurodegeneration in mixed neuron-glia coculture through the inhibition of microglial overactivation, and the subsequent reduction in the levels of proinflammatory cytokines, free radicals and reactive oxygen species (19). In the present study, the DeltaVision Elite microscopy imaging system was used to analyze the effects of DM on the production of proinflammatory mediators.

\section{Materials and methods}

Materials. The following reagents were used in this study: DM and LPS (Sigma-Aldrich, St. Louis, MO, USA); rabbit monoclonal antibodies against $\beta$-actin and $N F-\kappa B$ p65 (Abcam, Cambridge, MA, USA); mouse monoclonal anti-HSP60 and anti-heat shock factor 1 (HSF1) antibodies (Stressgen $^{\circledR}$, San Diego, CA, USA; Enzo Life Sciences, Inc., Farmingdale, NY, USA); rabbit polyclonal anti-caspase-3 antibody (Cell Signaling Technology, Inc., Beverly, MA, USA); proteinase inhibitor cocktails (Merck Chemicals, Whitehouse Station, NJ, USA); IL-6, IL-1 $\beta$ and TNF- $\alpha$ ELISA kits (eBioscience, San Diego, CA, USA); bicinchoninic acid (BCA) and enhanced chemiluminescence (ECL) kits (Pierce Biotechnology, Inc., Rockford, IL, USA); Dulbecco's modified Eagle's medium (DMEM) and fetal bovine serum (FBS; Gibco-BRL, Grand Island, NY, USA); Griess reagent and iNOS kits (Nanjing Jiancheng Bioengineering Institute, Nanjing, China); Cell Counting kit-8 (CCK-8; Beyotime Biotech, Jiangsu, China); and fluorescein isothiocyanate (FITC)-conjugated Affinipure goat anti-rabbit and tetramethylrhodamine (TRITC)-conjugated Affinipure goat anti-mouse antibodies (Abcam). All additional materials were purchased from ZSGB-BIO (Beijing, China), unless otherwise stated.

Microglial cell culture. BV2 mouse microglial cells (Shanghai Cell Bank, Shanghai, China) were cultured in DMEM supplemented with $10 \%$ FBS, penicillin (100 units $/ \mathrm{ml}$ ) and streptomycin $(100 \mathrm{~g} / \mathrm{ml})$. The cultures were maintained at $37^{\circ} \mathrm{C}$ in a humidified incubator with $95 \% \mathrm{O}_{2}$ and $5 \% \mathrm{CO}_{2}$. The cells were treated with $1 \mu \mathrm{g} / \mathrm{ml}$ LPS for $30 \mathrm{~min}$, followed by administration of $10,25,50,80$ or $100 \mu \mathrm{M}$ DM (dissolved in PBS) for $24 \mathrm{~h}$.

Cell viability assay. Cell viability was measured using a CCK-8 assay. BV2 cells $\left(5 \times 10^{4}\right.$ cells in $100 \mu \mathrm{l} /$ well $)$ were seeded in 96 -well plates. CCK-8 solution $(10 \mu \mathrm{l})$ was added to each well and the cultures were incubated at $37^{\circ} \mathrm{C}$ for $90 \mathrm{~min}$. The absorbance at $450 \mathrm{~nm}$ was measured using a SmartSpec Plus Spectrophotometer (Bio-Rad, Beijing, China). The results are plotted as the means \pm standard deviation (SD) of three separate experiments with four determinations per experiment for each experimental condition. The cell survival ratio was calculated, normalizing the results to the control group (without LPS+DM).

ELISA. The levels of IL-6, IL-1 $\beta$, HSP60 and TNF- $\alpha$ present in the culture medium, were quantified according to the manufacturer's instructions for the respective ELISA kits. The absorbance was determined at $450 \mathrm{~nm}$ using a Model 680 microplate reader (Bio-Rad, Beijing, China).

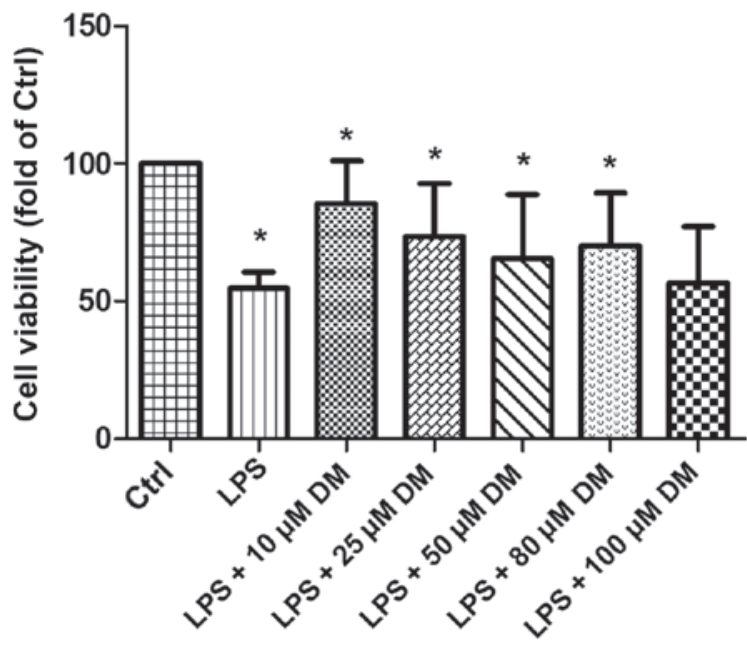

Figure 1. Dextromethorphan (DM) increases BV2 microglial cell viability. BV2 microglial cells were treated with lipopolysaccharide (LPS; $1 \mu \mathrm{g} / \mathrm{ml}$ ) for $0.5 \mathrm{~h}$, followed by treatment with various concentrations of DM $(10,25$, 50,80 or $100 \mu \mathrm{M}$ ) for $24 \mathrm{~h}$. The viability of the untreated cells was set to 100 . The viability of the LPS- and DM-treated cells is expressed as the percentage of that of the untreated control cells. The data represent the means \pm standard error of the mean from three separate experiments, performed in triplicate. ${ }^{*} \mathrm{P}<0.05$, LPS group as compared with the control group; DM groups as compared with the LPS group. Ctrl, control.

Western blot analysis. Western blotting was performed according to a standard method. Briefly, BV2 cells were washed with PBS three times and lyzed in radioimmunoprecipitation assay buffer. The protein concentration was determined using the BCA kit according to the manufacturer's instructions. Equal quantities of each protein sample were separated by SDS-PAGE and then transferred to a polyvinylidene difluoride membrane. The membranes were blocked with $5 \%$ milk powder and incubated with the respective primary antibodies (anti-P65 1;1,000; anti-caspase, 1:1,000; anti-HSP60, 1:1,000; anti-HSF-1, 1:200; and anti- $\beta$-actin, 1:5,000) in Tris-buffered saline with Tween-20 (TBST) overnight at $4^{\circ} \mathrm{C}$. Subsequent to rinsing in milk-TBST, the blots were incubated with horseradish peroxidase-conjugated secondary antibodies $(1: 5,000)$. The target proteins were detected by using the ECL detection system and X-ray films.

Immunofluorescence. BV2 cells $\left(5 \times 10^{4}\right.$ cells in $\left.100 \mu \mathrm{l} / \mathrm{well}\right)$ were seeded on coverslips in 24-well plates. Following $24 \mathrm{~h}$ incubation, the cells were treated with LPS $(1 \mu \mathrm{g} / \mathrm{ml})$ for $1 \mathrm{~h}$ and then incubated with the indicated concentrations of DM for $24 \mathrm{~h}$. Subsequently, the cells were washed twice with PBS, fixed with 4\% paraformaldehyde in PBS for $15 \mathrm{~min}$, washed three times with PBS and then permeabilized with $0.5 \%$ Triton X-100 in PBS for 20 min. The cells were again washed three times with PBS and blocked with $5 \%$ bovine serum albumin for $1 \mathrm{~h}$ at $37^{\circ} \mathrm{C}$. Following blocking, the cells were incubated with primary antibodies (anti-P65 1;100; anti-caspase, 1:100; anti-HSP60, 1:200; anti-HSF-1, 1:50; and anti-iNOS, 1:100) in PBS overnight at $4^{\circ} \mathrm{C}$, then rinsed with PBS, and incubated with the FITC- and TRITC-conjugated secondary antibodies $(1: 1,000)$ for $1 \mathrm{~h}$ at $37^{\circ} \mathrm{C}$. The cells were then washed with PBS, stained with DAPI and then mounted. Images were captured at magnification, x400 using 
A

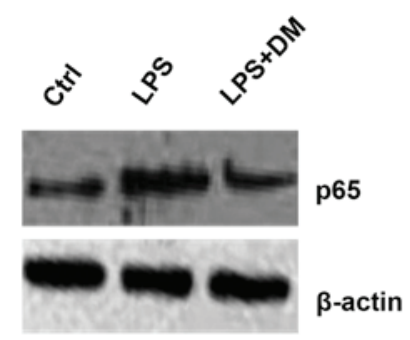

B

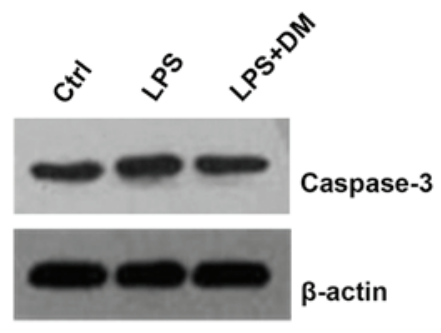

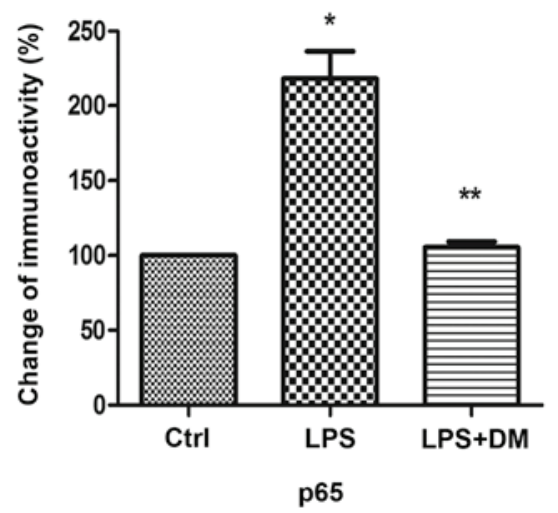

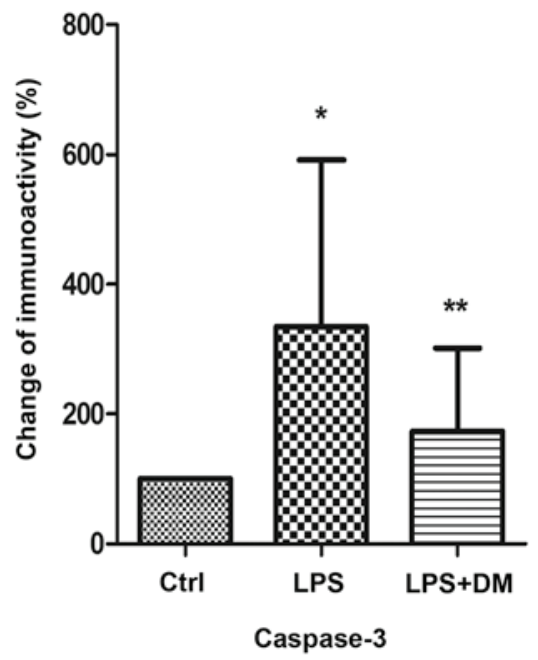

Figure 2. Dextromethorphan (DM) inhibits the increased expression of nuclear factor- $\kappa \mathrm{B}$ (NFאB) $\mathrm{p} 65$ and caspase-3 in lipopolysaccharide (LPS)-stimulated BV2 microglia. The cells were pretreated with LPS for $0.5 \mathrm{~h}$, followed by incubation with $10 \mu \mathrm{M}$ DM for $24 \mathrm{~h}$. The lysates were probed by immunoblotting with antibodies against $\mathrm{NFKB}$ p65 and $\beta$-actin (used as an internal loading control). (A) Analysis of p65 protein expression levels by western blotting. The right panel shows the ratio of $\mathrm{p} 65 / \beta$-actin signal intensity in each group. (B) Analysis of the Caspase-3 protein expression levels by western blotting. The right panel shows the ratio of caspase- $3 / \beta$-actin signal intensity in each group. Each result was derived from at least six independent cultures. The data represent the means \pm standard error of the mean. $\mathrm{P}<0.05$, as compared with the control group. ${ }^{* *} \mathrm{P}<0.05$, as compared with the LPS group. Ctrl, control.

in LPS-stimulated BV2 microglia were investigated using western blotting. The levels of the p65 subunit of NFאB were significantly increased following LPS treatment, as compared with the control $(\mathrm{P}<0.05)$, but were markedly inhibited by DM, as compared with LPS treatment alone $(\mathrm{P}<0.05$; Fig. 2A). Subsequent to LPS stimulation, caspase-3 expression was found to be significantly suppressed following DM treatment, as compared with LPS treatment only $(\mathrm{P}<0.05$; Fig. 2B).

DM inhibits HSP60 protein expression and release in LPS-stimulated BV2 microglia. The levels of HSP60 expression and release were detected in activated BV2 cells. The western blotting results demonstrated that LPS significantly enhanced HSP60 expression levels, as compared with those of the control group $(\mathrm{P}<0.05)$, but DM significantly inhibited this increase, as compared with LPS treatment alone $(\mathrm{P}<0.05$; Fig. 3A). HSF-1 has been shown to bind with the heat shock element on the HSP60 promoter to regulate HSP60 gene expression (20). Therefore, the HSF-1 expression levels were analyzed and were found to be significantly upregulated by LPS $(\mathrm{P}<0.05)$, but significantly downregulated by additional DM treatment $(\mathrm{P}<0.05)$. This indicated that HSP60 expression in the LPS group as compared with those in the DM group (Fig. 5A). The statistical analysis is shown in Fig. 5B and is consistent with the findings from the western blotting and ELISA. From these data, DM may be considered to effectively inhibit HSP60, HSF-1, NF- $\mathrm{B}$, caspase-3 and iNOS expression in LPS-stimulated microglia.

\section{Discussion}

In the present study, treatment with $10 \mu \mathrm{MDM}$ was demonstrated to effectively inhibit LPS-induced activation of microglia. DM reduced the expression levels of NFKB, caspase-3, HSP60, HSF-1 and iNOS in microglia, and effectively suppressed the release into the culture medium of HSP60, NO and several proinflammatory cytokines, including TNF- $\alpha$, IL- 6 and IL-1 $\beta$, in microglia stimulated by LPS. Therefore, the data suggest that DM may be a useful therapeutic agent in the treatment of inflammatory diseases.

The activation of microglia is important in neural parenchymal defence against infectious diseases, as well as inflammation, trauma, ischaemia, brain tumors and neurodegeneration (22). The activated microglia secrete various proinflammatory and neurotoxic factors that are hypoth- 
A
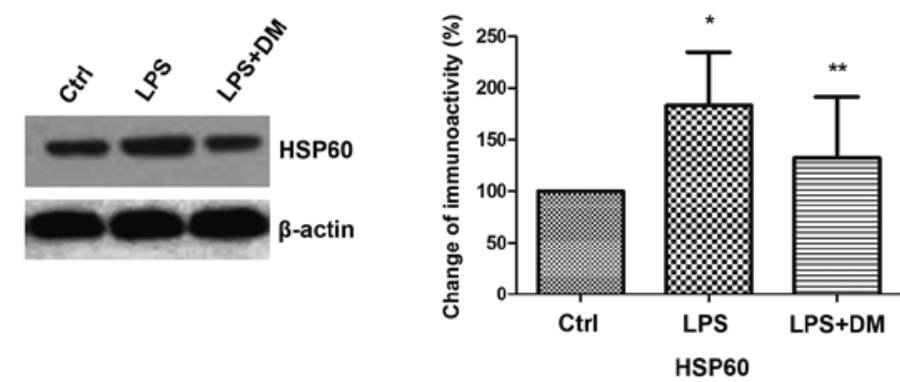

B
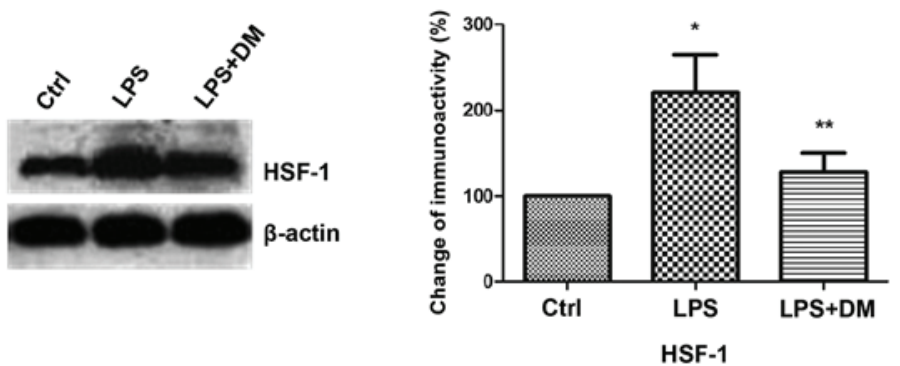

C

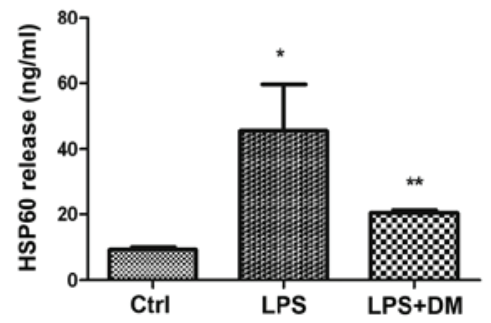

Figure 3. Dextromethorphan (DM) inhibits the increased expression and release of heat shock protein 60 (HSP60) and heat shock factor 1 (HSF-1) expression in lipopolysaccharide (LPS)-stimulated BV2 microglia. BV2 cells were pretreated with LPS for $0.5 \mathrm{~h}$, followed by incubation with $10 \mu \mathrm{M}$ DM for $24 \mathrm{~h}$. (A) Analysis of protein expression by western blotting, using antibodies against HSP60 and $\beta$-actin (as an internal loading control). The right panel shows the ratio of HSP60/ $\beta$-actin signal intensity. (B) The lysates were probed by immunoblotting with antibodies against HSF1 and $\beta$-actin. The right panel shows the ratio of HSF1/ $\beta$-actin signal intensity. (C) Extracellular levels of HSP60 were detected by enzyme-linked immunosorbent assay. The data represent the means \pm standard error of the mean from three independent experiments performed in triplicate. ${ }^{*} \mathrm{P}<0.05$, compared with the control group. ${ }^{* *} \mathrm{P}<0.05$, as compared with the LPS group. Ctrl, control.
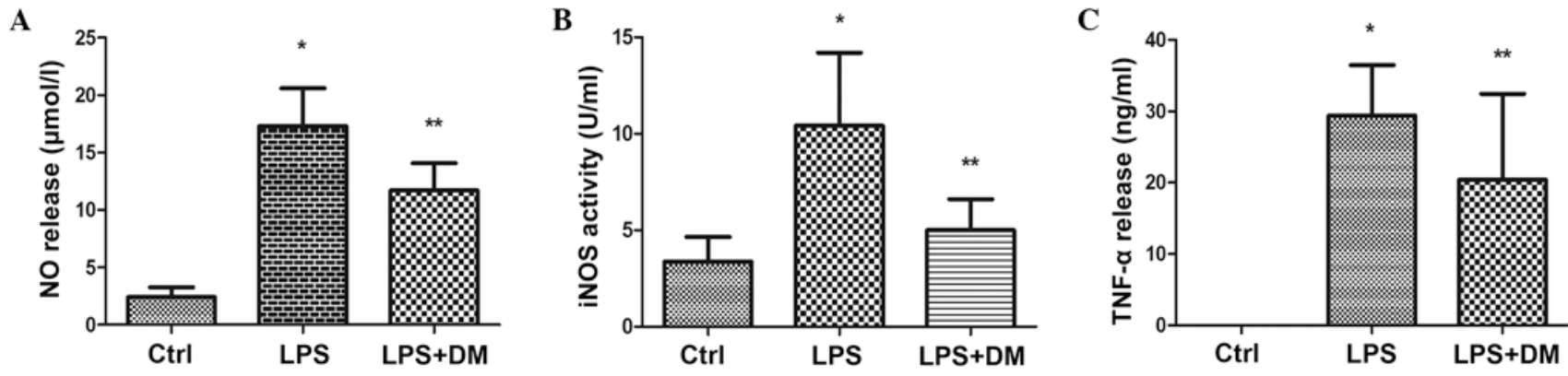

D

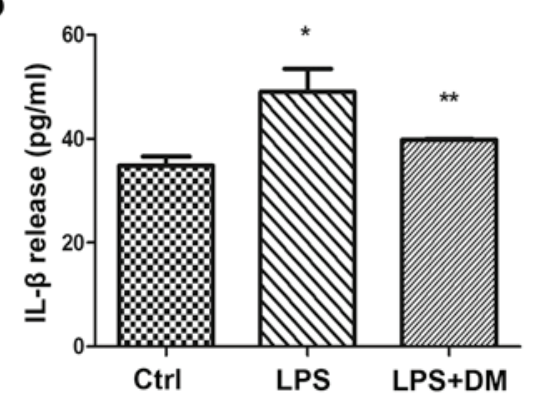

$\mathbf{E}$

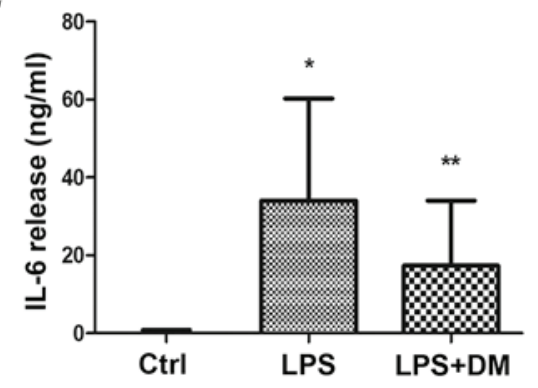

Figure 4. Dextromethorphan (DM) reduces the release of nitric oxide (NO), inducible NO synthase (iNOS), tumor necrosis factor- $\alpha$ (TNF- $\alpha$ ), interleukin (IL)-6 and IL-1 $\beta$ in lipopolysaccharide (LPS)-stimulated BV2 microglia. The cells were pretreated with LPS for $0.5 \mathrm{~h}$, followed by incubation with $10 \mu \mathrm{M}$ DM for $24 \mathrm{~h}$. Extracellular levels of (A) NO and (B) iNOS were assayed with Griess reagent and iNOS kits, and (C) TNF- $\alpha$, (D) IL-1 $\beta$ and (E) IL-6 were measured by ELISA. The data represent the means \pm standard error of the mean of three separate experiments performed in triplicate. "P<0.05, as compared with the control group. ${ }^{* *} \mathrm{P}<0.05$, as compared with the LPS group. Ctrl, control. 
A

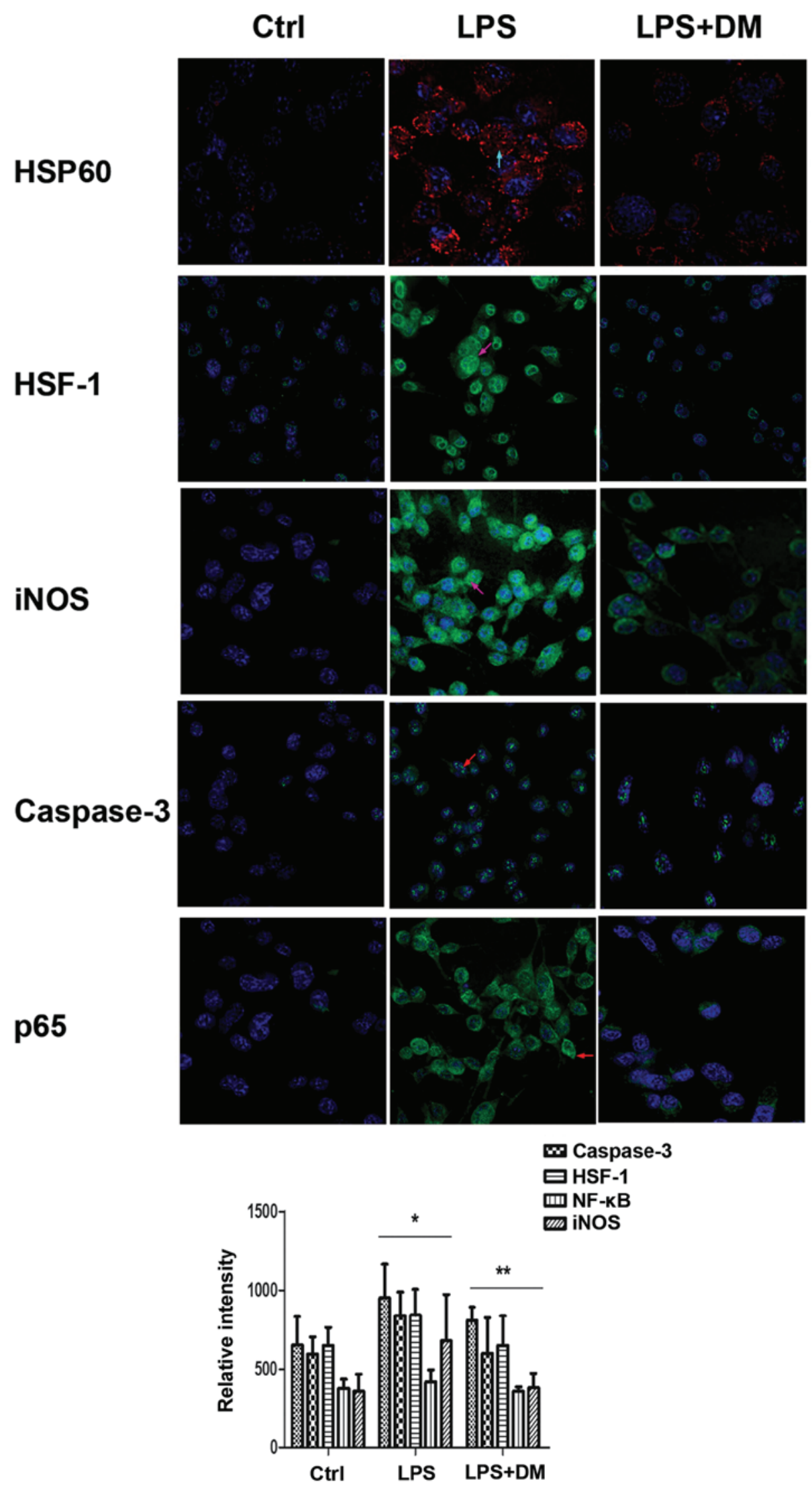

Figure 5. Dextromethorphan (DM) inhibits heat shock protein 60 (HSP60), heat shock factor 1 (HSF-1), nuclear factor- $\kappa \mathrm{B}$ (NFKB), caspase-3 and inducible nitric oxide synthase (iNOS) expression in LPS-stimulated BV2 microglial cells, as detected by immunofluorescence. The cells were pretreated with lipopolysaccharide (LPS) for $0.5 \mathrm{~h}$, followed by incubation with $10 \mu \mathrm{M}$ DM for $24 \mathrm{~h}$. (A) The expression fluorescence intensity of HSP60, HSF-1, iNOS, NFKB and caspase-3 varied between the control, LPS and LPS + DM groups. The arrows indicate the various subcellular localization of the respective proteins in the cells. All the images were produced by merging the cytoplasmic and nuclear images (digital image capture, magnification, x400). (B) Statistical analysis of the signal intensities of HSP60, HSF-1, NFאB, caspase-3 and iNOS. The data represent the means \pm standard error of the mean of each separate experiment performed. ${ }^{*} \mathrm{P}<0.05$, as compared with the Ctrl group. ${ }^{* *} \mathrm{P}<0.05$, as compared with the LPS group. Ctrl, control. 
inhibited caspase-3 and the NFאB downstream mediator $\mathrm{p} 65$, suggesting that the anti-inflammatory effects of DM may be a result of inhibition of the $\mathrm{NF \kappa B}$ signaling pathway.

HSP60 is primarily considered to be a mitochondrial protein, but may translocate to the plasma membrane, even being released extracellularly upon stress, which is a process that has been demonstrated to be induced by the NFкB-p65 cascade (21). Extracellular HSP60 may become toxic by targeting self-reactive $\mathrm{T}$ cells in inflammatory diseases (37). HSP60 gene expression is regulated by the corresponding transcription factor, HSF-1, which binds to the HSP60 gene promoter. $\mathrm{NF} \kappa \mathrm{B}$ has also been shown to initiate transcription of the HSP60 stress gene, which elicits a potent proinflammatory response in innate immune cells (38). TNF- $\alpha$ is a mediator of $\mathrm{NF \kappa B}$ signaling and induces an increase in the expression levels of HSP60, which has been shown to be reversed by p65 inhibition (38). Therefore, in the present study, HSP60 expression in BV2 cells and extracellular release, as well as TNF- $\alpha$ levels in the culture medium were measured, following NFאB activation by LPS. The results reveal that DM suppressed HSP60 expression and release, and also reduced extracellular TNF- $\alpha$ levels.

Microglial activation is widely known to produce proinflammatory cytokines, NO and iNOS. This was confirmed in the present study by measuring the levels of IL-1 $\beta$, IL-6, $\mathrm{NO}$ and iNOS in the culture medium of BV2 cells stimulated by LPS. The iNOS gene is under the transcriptional control of various inflammatory mediators, including cytokines and LPS. NO, a product of iNOS, has been found to be important as a signaling molecule in a number of areas of the body, as well as acting as a cytotoxic or regulatory effector molecule of the innate immune response (39). However, in the present study, following DM treatment, IL-1 $\beta$, IL-6, NO and iNOS expression levels were markedly inhibited.

Combined with results from previous studies, the findings from the present study indicate that DM may exert neuroprotective action through the inhibition of the $\mathrm{NF} \kappa \mathrm{B}$ signaling pathway to prevent the overactivation of microglia.

\section{Acknowledgements}

This study was supported by the National Natural Science Foundation of China (grant nos. 31060140 and 31260243), the Project-sponsored by SRF for ROCS and State Education Ministry. Additional funding was provided to Dr Yin Wang by the Program for New Century Excellent Talents in University.

\section{References}

1. Block ML, Zecca L and Hong JS: Microglia-mediated neurotoxicity: uncovering the molecular mechanisms. Nature Rev Neurosci 8: 57-69, 2007.

2. Hanisch UK and Kettenmann H: Microglia: active sensor and versatile effector cells in the normal and pathologic brain. Nat Neurosci 10: 1387-1394, 2007.

3. Gehrmann J, Matsumoto Y and Kreutzberg GW: Microglia: intrinsic immuneffector cell of the brain. Brain Res Rev 20 269-287, 1995

4. Innamorato NG, Lastres-Becker I and Cuadrado A: Role of microglial redox balance in modulation of neuroinflammation. Curr Opin Neurol 22: 308-314, 2009.

5. Lynch MA: The multifaceted profile of activated microglia. Mol Neurobiol 40: 139-156, 2009.

6. Li YH, Teng P, Wang Y, et al: Expression and regulation of HSP60 in activated microglia cells. J Ningxia Med Coll 8: 712-714, 2011.
7. Zhang D, Sun L, Zhu H, et al: Microglial LOX-1 reacts with extracellular HSP60 to bridge neuroinflammation and neurotoxicity. Neurochem Int 61: 1021-1035, 2012.

8. Lehnardt S, Schott E, Trimbuch T, et al: A vicious cycle involving release of heat shock protein 60 from injured cells and activation of toll-like receptor 4 mediates neurodegeneration in the CNS. J Neurosci 28: 2320-2331, 2008.

9. Thanos S, Mey J and Wild M: Treatment of the adult retina with microglia-suppressing factors retards axotomy-induced neuronal degradation and enhances axonal regeneration in vivo and in vitro. J Neurosci 13: 455-466, 1993.

10. Thanos S: The relationship of microglial cells to dying neurons during natural neuronal cell death and axotomy-induced degeneration of the rat retina. Eur J Neurosci 3: 1189-1207, 1991.

11. Teng P,Li YH, Cheng WJ, et al: Neuroprotective effects of Lycium barbarum polysaccharides in lipopolysaccharide-induced BV2 microglia cells. Mol Med Rep 7: 1977-1981, 2013.

12. Rangarajan P, Eng-Ang L and Dheen ST: Potential drugs targeting microglia: current knowledge and future prospects. CNS Neurol Disord Drug Targets 12: 799-806, 2013.

13. Shin EJ, Bach JH, Lee SY, Kim JM, Lee JJ and Hong JS et al: Neuropsychotoxic and neuroprotective potentials of dextromethorphan and its analogs. J Pharmacol Sci 116: 137-148, 2011.

14. Mousavi SA, Saadatnia M, Khorvash F, Hoseini T and Sariaslani P: Evaluation of the neuroprotective effect of dextromethorphan in the acute phase of ischaemic stroke. Arch Med Sci 7: 465-469, 2011.

15. Liu B, Du L and Hong JS: Naloxone protects rat dopaminergic neurons against inflammatory damage through inhibition of microglia activation and superoxide generation. J Pharmacol Exp Ther 293: 607-617, 2000

16. Liu Y, Qin L, Wilson BC, et al: Inhibition by naloxone stereoisomers of beta-amyloid peptide (1-42)-induced superoxide production in microglia and degeneration of cortical and mesencephalic neurons. J Pharmacol Exp Ther 302: 1212-1219, 2002.

17. Chang RC, Rota C, Glover RE, Mason RP and Hong JS: A novel effect of an opioid receptor antagonist, naloxone, on the production of reactive oxygen species by microglia: a study by electron paramagnetic resonance spectroscopy. Brain Res 854: 224-229, 2000

18. Liu B, Du L, Kong LY, et al: Reduction by naloxone of lipopolysaccharide-induced neurotoxicity in mouse cortical neuron-glia co-cultures. Neuroscience 97: 749-756, 2000.

19. Liu Y, Qin L, Li G, et al: Dextromethorphan protects dopaminergic neurons against inflammation-mediated degeneration through inhibition of microglial activation. J Pharmacol Exp Ther 305: 212-218, 2003.

20. Li G,Liu Y,Tzeng NS, et al: Protective effect of dextromethorphan against endotoxic shock in mice. Biochem Pharmacol 69: 233-240, 2005 .

21. Hansen JJ, Bross P, Westergaard M, et al: Genomic structure of the human mitochondrial chaperonin genes: HSP60 and HSP10 are localised head to head on chromosome 2 separated by a bidirectional promoter. Hum Genet 112: 71-77, 2003.

22. Lin L, Kim SC, Wang Y, Gupta S, et al: HSP60 in heart failure: abnormal distribution and role in cardiac myocyte apoptosis. Am J Physiol Heart Circ Physiol 293: H2238-H2247, 2007.

23. Kreutzberg GW: Microglia: a sensor for pathological events in the CNS. Trends Neurosci 19: 312-318, 1996.

24. Park E, Kim DY and Chun HS: Resveratrol inhibits lipopolysaccharide-induced phagocytotic activity in BV2 cells. J Korean Soc Appl Biol Chem 55: 803-807, 2012.

25. Karlstetter M, Lippe E, Walczak Y, et al: Curcumin is a potent modulator of microglial gene expression and migration. J Neuroinflammation 8: 125, 2011.

26. Park HY, Han MH, Park C, et al: Anti-inflammatory effects of fucoidan through inhibition of NF- $\mathrm{B}, \mathrm{MAPK}$ and Akt activation in lipopolysaccharide-induced BV2 microglia cells. Food Chem Toxicol 49: 1745-1752, 2011.

27. Britton P, Lu XC, Laskosky MS and Tortella FC: Dextromethorphan protects against cerebral injury following transient, but not permanent, focal ischemia in rats. Life Sci 60: 1729-1740, 1997.

28. Lesage AS, De Loore KL, Peeters L and Leysen JE: Neuroprotective sigma ligands interfere with the glutamate-activated NOS pathway in hippocampal cell culture. Synapse 20: 156-164, 1995 .

29. Prince DA and Feeser HR: Dextromethorphan protects against cerebral infarction in a rat model of hypoxia-ischemia. Neurosci Lett 85: 291-296, 1988. 
30. Berman FW and Murray TF: Characterization of $\left[{ }^{3} \mathrm{H}\right] \mathrm{MK}-801$ binding to $\mathrm{N}$-methyl-D-aspartate receptors in cultured rat cerebellar granule neurons and involvement in glutamate-mediated toxicity. J Biochem Toxicol 11: 217-226, 1996.

31. Craviso GL and Musacchio JM: High-affinity dextromethorphan binding sites in guinea pig brain. I. Initial characterization. Mol Pharmacol 23: 619-628, 1983a.

32. Craviso GL and Musacchio JM: High-affinity dextromethorphan binding sites in guinea pig brain. II. Competition experiments. Mol Pharmacol 23: 629-640, 1983b.

33. Khasnavis S, Jana A, Roy A, et al: Suppression of nuclear factor- $\kappa \mathrm{B}$ activation and inflammation in microglia by physically modified saline. J Biol Chem 287: 29529-29542, 2012.

34. $\mathrm{Gu} \mathrm{JH}, \mathrm{Ge} \mathrm{JB}, \mathrm{Li} \mathrm{M}$, et al: Inhibition of NF- $\kappa \mathrm{B}$ activation is associated with anti-inflammatory and anti-apoptotic effects of Ginkgolide B in a mouse model of cerebral ischemia/reperfusion injury. Eur J Pharm Sci 47: 652-660, 2012.

35. Woods DC, White YA, Dau C and Johnson AL: TLR4 activates $\mathrm{NF}-\kappa \mathrm{B}$ in human ovarian granulosa tumor cells. Biochem Biophys Res Commun 409: 675-680, 2011.
36. Soria JA, Arroyo DS, Gaviglio EA, et al: Interleukin 4 induces the apoptosis of mouse microglial cells by a caspase-dependent mechanism. Neurobiol Dis 43: 616-624, 2011.

37. Burguillos MA, Deierborg T, Kavanagh E, et al: Caspase signalling controls microglia activation and neurotoxicity. Nature 472: 319-324, 2011.

38. Kim SC, Stice JP, Chen L, et al: Extracellular heat shock protein 60, cardiac myocytes and apoptosis. Circ Res 105: 1186-1195, 2009

39. Wang Y, Chen L, Hagiwara $\mathrm{N}$ and Knowlton AA: Regulation of heat shock protein 60 and 72 expression in the failing heart. J Mol Cell Cardiol 48: 360-366, 2010.

40. Kröncke KD, Fehsel K and Kolb-Bachofen V: Inducible nitric oxide synthase and its product nitric oxide, a small molecule with complex biological activities. Biol Chem Hoppe Seyler 376: 327-343, 1995. 